\title{
RELATIONSHIP BETWEEN SERUM LIPID PROFILES AND SEVERITY OF RESPIRATORY DISTRESS IN PRETERM INFANTS
}

\author{
Sanjay D1, Mohamed Haseen Basha², Gururaj3, Chandrashekar Gouli, Ashoka Anandappa 5, Latha Gowdru Shamanur 6 , \\ Nijalingappa Kenchappa Kalappanavar7, Prasad Budihal Shivana Gowda ${ }^{8}$
}

\author{
${ }^{1}$ Associate Professor, Department of Paediatrics, SSIMS \& RC, Davangere. \\ ${ }^{2}$ Assistant Professor, Almareefa College of Medicine, Riyadh. \\ ${ }^{3}$ Senior Resident, Department of Paediatrics, SSIMS \& RC, Davangere. \\ ${ }^{4}$ Associate Professor, Department of Paediatrics, SSIMS \& RC, Davangere. \\ ${ }^{5}$ Associate Professor, Department of Paediatrics, JJMMC, Davangere. \\ 6 Professor, Department of Paediatrics, SSIMS \& RC, Davangere. \\ 7 Professor, Department of Paediatrics, SSIMS \& RC, Davangere. \\ ${ }^{8}$ Professor, Department of Paediatrics, SSIMS \& RC, Davangere.
}

\begin{abstract}
OBJECTIVE

To study serum lipid profiles in preterm infants and their relationship to severity of Respiratory Distress Syndrome (RDS).

\section{METHODS}

The study was conducted on 29 neonates who were admitted to NICU with prematurity and respiratory distress. Respiratory distress was classified based on Downes' clinical scoring into mild distress (Score of 1-3), moderate distress (Score of 4-6) \& sever distress (Score of 7-10). The venous blood samples were collected within 6 hours after birth for biochemical analysis of serum lipid levels Triglycerides (TG), Low Density Lipoprotein (LDL), High Density Lipoprotein (HDL), Very Low Density Lipoprotein (VLDL), Total Cholesterol "TC," and their levels were analysed with the severity of respiratory distress.
\end{abstract}

\section{RESULTS}

Preterm infants with severe respiratory distress were found to have lower mean levels of serum lipid levels (TG, LDL, HDL, VLDL and TC) compared to mild and moderate respiratory distressed preterm new-borns and the results were found to be statistically significant $(\mathrm{p}<0.001)$.

\section{CONCLUSION}

Respiratory distress is more sever in neonates with lower serum lipid levels. Severity of RDS is inversely proportional to serum lipid levels.

\section{KEYWORDS}

Serum Lipid Levels, Respiratory Distress Syndrome, Preterm Infants.

HOW TO CITE THIS ARTICLE: Sanjay D, Basha MH, Gururaj, et al. "Relationship between serum lipid profiles and severity of respiratory distress in preterm infants." Journal of Evolution of Medical and Dental Sciences 2015; Vol. 4, Issue 104, December 28; Page: 16954-16956, DOI: 10.14260/jemds/2015/2557

\section{INTRODUCTION}

RDS (Respiratory Distress Syndrome), which occurs exclusively in premature infants is one of the common cause of neonatal admission and morbidity. Severity and incidence is inversely proportional to gestational age. ${ }^{1}$ RDS occurs because of deficiency of Surfactant. When compared to matured lung surfactant, the surfactant found in preterm RDS is low in desaturated phosphatidylcholine, phosphatidylglycerol and less of surfactant protein. Surfactant is synthesized and secreted from the type II pneumocytes at 24 to 34 weeks of gestation, the composition of which is $80 \%$ phospholipids and $10 \%$ of neutral lipids (Mainly cholesterol) and $10 \%$ of proteins. ${ }^{2}$ Lung cholesterol is regulated by LDL, HDL, which stimulates alveolar type II cells to secrete surfactant.3,4 so lipid metabolism is vital for lung development and essential for surfactant synthesis.

Financial or Other, Competing Interest: None.

Submission 18-12-2015, Peer Review 19-12-2015,

Acceptance 24-12-2015, Published 28-12-2015.

Corresponding Author:

Dr. Sanjay D,

1665/42, Nandanam

SS layout, A block,

Davangere.

E-mail: drsanjay78@yahoo.com

DOI:10.14260/jemds/2015/2557
Lane et al. study shows that cord lipid levels might be with the potential to detect those infants at risk for RDS that develops postnatally. ${ }^{1}$

\section{MATERIALS AND METHODS}

The study was conducted in Dept. of Paediatrics, SSIMS and RC, Davanagere from January 2015 to September 2015. Inclusion criteria were Preterm infants admitted to NICU with RDS. Exclusion criteria were LGA, asphyxiated infants, congenital anomaly, Pregnancies complicated by PIH, Pre-eclampsia, DM, Thyroid, Adrenal problems. Infants whose mother has taken drugs affecting lipid metabolism such as steroids (Except for foetal lung maturation).

Four hundred and fourteen infants were admitted to NICU in the study period of which 29 infants were enrolled for the study. Informed consent was taken from one of the parent before enrolment and ethical clearance was taken from Ethical Committee of Institute. Once the infant met inclusion criteria, gestational age, gender, birth weight, height, ponderal index, Apgar score, Downe's score, mode of delivery were recorded in a predesigned proforma. Gestational age is calculated from LMP and modified New Ballard's score. Respiratory distress was diagnosed on the basis of clinical criteria such as retraction of chest wall, cyanosis, hypoxemia, hypercarbia in $\mathrm{ABG}$ and radiological feature such as reticulogranular pattern and air bronchogram. The severity of RDS is further divided into Mild (1-3), Moderate (4-6) and Severe (7-10) by using 
Downe's score. Blood samples were collected from umbilical vein and sent for analysis of lipid profile. Serum triglycerides, HDL, LDL, VLDL, Cholesterol were measured using standard enzymatic methods with fully automated analyser.

\section{MATERIALS AND METHODS}

The study was conducted in Dept. of Paediatrics, SSIMS and RC, Davanagere from January 2015 to September 2015. Inclusion criteria were Preterm infants admitted to NICU with RDS Exclusion criteria were LGA, asphyxiated infants, congenital anomaly, Pregnancies complicated by PIH, Pre-eclampsia, DM, Thyroid, Adrenal problems. Infants whose mother has taken drugs affecting lipid metabolism such as steroids (Except for foetal lung maturation).

Four hundred and fourteen infants were admitted to NICU in the study period of which 29 infants were enrolled for the study. Informed consent was taken from one of the parent before enrolment and ethical clearance was taken from Ethical committee of institute. Once the infant met inclusion criteria, gestational age, gender, birth weight, height, ponderal index, Apgar score, Downes score, mode of delivery were recorded in a predesigned proforma. Gestational age is calculated from LMP and modified New Ballard's score.

Respiratory distress was diagnosed on the basis of clinical criteria such as retraction of chest wall, cyanosis, hypoxemia, hypercarbia in ABG and radiological feature such as reticulogranular pattern and air bronchogram. The severity of RDS is further divided into Mild (1-3), Moderate (4-6) and Severe (7-10) by using Downe's score. Blood samples were collected from umbilical vein and sent for analysis of lipid profile. Serum triglycerides, HDL, LDL, VLDL, Cholesterol were measured using standard enzymatic methods with fully automated analyser.

\section{STATISTICAL ANALYSIS}

Mean value and standard deviation have been used to define data in each group. These values were compared between groups of RDS. Unpaired t test was used to compare the means between the groups. One way ANOVA was for multiple group comparisons. $\mathrm{P}$ value of $<0.05$ was considered for statistical significance. And $<0.001$ is considered as highly significance. SRS version 7 software was used for data analysis.

\begin{tabular}{|c|c|c|c|}
\hline \multicolumn{4}{|c|}{ Severity of Distress and Lipid profile in RDS } \\
\hline Lipid & Severity of Distress & Mean & SD \\
\hline \multirow[t]{5}{*}{$\mathrm{Tg}$} & Mild & 63.3 & 4.9 \\
\hline & Moderate & 39.3 & 17.3 \\
\hline & Severe & 22.3 & 15.2 \\
\hline & $\mathrm{F}$ & 22.12 & - \\
\hline & $\mathrm{P}$ & $0.00^{* *}$ & - \\
\hline \multirow[t]{5}{*}{ LDL } & Mild & 62.6 & 3.8 \\
\hline & Moderate & 38.9 & 16.0 \\
\hline & Severe & 31.3 & 13.1 \\
\hline & $\mathrm{F}$ & 17.70 & - \\
\hline & $\mathrm{P}$ & $0.00^{* *}$ & - \\
\hline \multirow[t]{5}{*}{ VLDL } & Mild & 34.3 & 3.4 \\
\hline & Moderate & 18.1 & 9.3 \\
\hline & Severe & 9.6 & 9.2 \\
\hline & $\mathrm{F}$ & 25.104 & - \\
\hline & $\mathrm{P}$ & $0.00^{* *}$ & - \\
\hline \multirow[t]{5}{*}{ HDL } & Mild & 36.9 & 2.9 \\
\hline & Moderate & 30.5 & 5.7 \\
\hline & Severe & 24.7 & 3.3 \\
\hline & $\mathrm{F}$ & 20.06 & - \\
\hline & $\mathrm{P}$ & $0.00^{* *}$ & - \\
\hline \multirow[t]{5}{*}{ TC } & Mild & 145.7 & 6.5 \\
\hline & Moderate & 103.3 & 30.4 \\
\hline & Severe & 90.7 & 19.0 \\
\hline & $\mathrm{F}$ & 18.02 & - \\
\hline & $\mathrm{P}$ & $0.00^{* *}$ & - \\
\hline \multicolumn{2}{|c|}{ One Way ANOVA, ${ }^{*} \mathrm{P}<0.05 \mathrm{~S}$} & & \\
\hline & $\mathrm{P}<0.001, \mathrm{HS}$ & & \\
\hline
\end{tabular}

\section{RESULTS}

The study group consisted of 29 infants with gestational age ranging from 28-36 weeks, birth weight ranging from $800 \mathrm{gm}$ to $2500 \mathrm{gm}$. We found that total serum triglyceride level, VLDL, LDL, HDL and TC were significantly lower in neonates with severe RDS with $P$ value $<0.001$, while compared to groups with mild-moderate RDS. The study shows that as the lipid profile lowers the severity of RDS increases.

\section{DISCUSSION}

Factors during pregnancy and delivery, as well as certain diseases, can influence fetal and neonatal lipid metabolism.5,6 Lane et al. ${ }^{1}$ found that preterm infants developing respiratory distress post-natally had significantly lower cord serum lipid levels than those of normal term infants or preterm infants free of respiratory distress. Significantly lower cord serum lipid levels are evidence of reduced essential fatty acids and long-chain polyunsaturated fatty acid supply, which could inhibit fetal growth in utero, delaying maturation of fetal lungs. Wojcicka-Jagodzinska et al. ${ }^{7}$ speculated that a reduction in the cholesterol concentrations of amniotic fluid of hypertensive mothers in whose children the respiratory distress syndrome developed, might have a prognostic significance in the prediction of respiratory distress in early neonatal period.

Compared with the values of non-RDS infants, lower levels of cholesterol and HDL cholesterol found in infants with RDS indicated a limited ability to metabolize VLDL, probably related to lipoprotein lipase impairment. Reduced levels of serum HDL cholesterol found in infants with RDS and in their mothers suggest that it may have an important role on regulating surfactant synthesis. Voyno Yasenetskaya, et al. ${ }^{8}$ demonstrated that both LDL and HDL cholesterols stimulate primary cultures of type II cells to secrete phosphatidylcholine, the major phospholipid component of pulmonary surfactant. As many studies have already demonstrated that Low Lipid profile in infants can predispose to RDS we compared lipid profile to severity of RDS \& found that lesser the Lipid values more will be the severity of respiratory distress.

\section{CONCLUSION}

Hence the data demonstrate that serum lipid profile in preterm neonates is inversely proportional to severity of RDS, as lipid profile lowers severity increases. So early estimation of serum lipid levels in preterm neonates is helpful in predicting the severity of RDS.

\section{REFERENCES}

1. Lane DM, McConathy WJ, McCaffree MA, et al. Cord serum lipid and apolipoprotein levels in preterm infants with the neonatal respiratory distress syndrome. J Matern Fetal Neonatal Med 2002;11:118-125.

2. Hass MA, Longmore WJ. Surfactant cholesterol metabolism of the isolated perfused rat lung. Biochim Biophys Acta 1979;573:166-174.

3. King RJ. The surfactant system of the lung. Journal of Perinatology. 1974;33:2238-2247.

4. Hass MA, Longmore WJ. Regulation of lung surfactant cholesterol metabolism by serum lipoproteins. Lipids 1980;15:401-446.

5. Hardell LI. Serum lipids and lipoproteins at birth based on study of 2815 new-born infants. II. Relation between materno-fetal factors and concentration of triglycerides and cholesterol. ActaPaediatrScand 1981;285:11-20.

6. Merzouk H, Meghelli-Bouchenak M, el-Korso N, et al. Low birth weight at term impairs cord serum lipoprotein compositions and concentrations. Eur J Pediatr 1998;157:321-326. 
7. Wojcicka-Jagodzinska J, Romejko E, Smolarczyk R, et al. Respiratory distress in new-borns born to hypertensive mothers and protein, lipid and renal maturity indices and enzymatic activity in the amniotic fluid. Ginekol Pol 1989;60:485-488.
8. Voyno-Yasenetskaya TA, Dobbs LG, Erickson SK, et al. Low-density lipoprotein- and high-density lipoproteinmediated signal transduction and exocytosis in alveolar type II cells. Proc Natl Acad Sci USA 1993;90:4256-4260. 